\title{
ESTUDO DA EMBEBIÇÃO E DA VIABILIDADE DE SEMENTES DE MACADÂMIA (Macadamia integrifolia MAIDEN \& BETCHE)
}

\author{
E.O. ONO \\ Bióloga, Pós-Graduanda em Ciências Biológicas - Dep. de Botânica - IB/UNESP - CEP: 18618-000-Botucatu,SP. \\ J.D. RODRIGUES \\ Prof. Adjunto do Dep. de Botânica - IB/UNESP - CEP: 18618-000-Botucatu,SP. \\ J.C. SABINO \\ Estação Experimental de Tietê/IAC - CEP: 18530-000-Tietê,SP. \\ S.Z. de PINHO \\ Dep. de Bioestatítica - IB/UNESP - CEP: 18618-000-Botucatu,SP.
}

RESUMO: O presente trabalho teve como objetivo, verificar o tempo de armazenamento necessário para que seja atingida a viabilidade máxima e o tempo de embebição máxima de sementes de macadâmia (Macadamia integrifolia Maiden \& Betche var. IAC-4-20). As sementes foram pesadas e colocadas em recipientes com água para que ocorresse o processo da embebição, sendo realizada a pesagem a cada 6 horas. Pode-se concluir que a embebição foi máxima ao redor de 90 horas após o início da embebição. Para a análise da viabilidade das sementes, estas foram semeadas mensalmente, durante 12 meses a partir da colheita. Verificou-se que a viabilidade máxima das sementes é atingida, 4 meses após 0 início do armazenamento.

Descritores: noz-macadâmia, sementes, embebição.

\section{STUDY OF TIIE IMBIBITION AND VIABILITY OF MACADAMIA SEEDS (Macadamia integrifolia MAIDEN \& BETCIIE)}

\begin{abstract}
To verify the necessary storage time to reach maximum viability and the imbibition time of Macadamia integrifolia Maiden \& Betche var. IAC-4-20) seeds, they were weighted and disposed in water vessels for the imbibition process, evaluated through weighing in intervals of 6 hours. It is concluded that the imbibition was maximum at about $\mathbf{9 0}$ hours after the beginning of imbibition. With relation to the analysis of viability, the seeds were planted monthly, during 12 months, after seed harvest. Maximum viability of seeds was reached four months after the initiation of seed storage.
\end{abstract}

Key Words: macadamia-nuts, seeds, imbibition.

\section{INTRODUÇño}

A macadâmia (Macadamia integrifolia Maiden \& Betche), originária da Austrália c pertencente à família Proteaceae, apresenta frutos lisos, esféricos ou arredondados. As folhas são lisas quando novas, apresentando coloração bronzeada na senescência, surgindo $\mathrm{em}$ número de $3 \mathrm{~cm}$ em cada nó. As flores surgem em panículas, apresentando coloração branca (DIERBERGER \& MARINO NETTO, 1985).

No Brasil, esta espécic foi introduzida somente em 1931, primeiramente na região de Limeira, sendo atualmente encontrada em várias regiões do Estado de São Paulo. Esta nogueira produz nozes de excelente sabor, as quais são utilizadas "in natura" acompanhando aperitivos, na confecção de bolos, chocolates e sorvetes, substituindo a noz avelã e as amêndoas importadas, sendo bem accitas pela população (DIERBERGER \& MARINO NETTO, 1985).

Segundo SIMÃO (1971), o processo de propagação da macadâmia deve ser realizado através de sementes, tanto para a formação de mudas de pé-franco como para a formação de porta-enxerto. Quanto ao tempo de início da germinação das sementes de macadâmia, SIMÃO (1971) observou que essa ocorre entre 40 e 120 dias após a semeadura, dependendo do tratamento efetuado sobre as sementes.

OJIMA et al. (1976), relatam que a germinação dessas sementes inicia-se ao redor dos 40 dias após a semeadura, podendo ocorrer até o oitavo mês. 
Autores como HAMILTON \& FUKUNAGA (1959) e OJIMA et al. (1976) observaram em seus experimentos que a viabilidade das sementes de macadâmia é máxima com 4 a 5 meses de armazenamento, caindo bruscamente após esse periiodo e sendo praticamente nula aos doze meses. Ainda, SIMÃo (1971) recomenda que as sementes de macadâmia sejam semeadas dentro de 3 a 4 meses após a colheita.

Frente a esse problema, o principal objetivo do presente trabalho foi o de verificar o tempo de armazenamento necessário para que seja atingida a viabilidade máxima das sementes de macadâmia, estabelecendo, assim, a sua melhor época de semeadura após a colheita e facilitando a produção de mudas. Além disso, a velocidade de embebição das sementes foi observada, com o intuito de se verificar o tempo demandado pela embebição para chegar ao seu ponto de máximo; esta variável é importante para a realização de tratamentos que acelerem a germinação das sementes.

\section{MATERIAL E MÉTODOS}

As sementes de macadâmia (Macadamia integrifolia Maiden \& Betche), utilizadas no presente estudo, pertenciam à variedade IAC-4-2e provieram da Estação Experimental de Tietê, do Instituto Agronômico de Campinas-IAC.

Para observação do tempo decorrido até o momento em que fosse atingido o ponto de embebição máxima, foram utilizados 12 recipientes (12 repetições) com capacidade de um litro, contendo 30 sementes cada um. As sementes foram pesadas, em balança analítica, antes do início do processo de embebição. Depois, aos recipientes foi adicionada água suficiente para cobrir todas as sementes, realizando-se a pesagem destas a cada 6 horas, até o momento em que a diferença entre duas pesagens subsequentes fosse desprezível, em torno de $0,1 \mathrm{~g}$. Durante a embebição, as sementes ficaram expostas à temperatura ambiente.

A partir dos resultados obtidos, foram calculadas as médias dos pesos das 30 sementes para cada tempo. Estas médias aumentaram ao longo do tempo, rapidamente no início do processo de embebição, tendendo a um valor constante, caracterizando a existência de uma assíntota. Tal fato define o ajuste de uma função de Mitscherlich.

A viabilidade das sementes foi observada mensalmente, durante 12 meses, a partir de coleta das sementes realizada no mês de maio. Para tal,
50 sementes por repetição foram colocadas em bandejas (2 repetições) contendo areia lavada, posteriormente levada a germinador a uma temperatura de $25^{\circ} \mathrm{C}$, durante 90 dias. Decorrido esse periodo, realizou-se a contagem de sementes germinadas, e os resultados foram submetidos à análise de variância (teste $F$ ), sendo as médias comparadas atraves do teste de Tukey com significância à nível de 5\% (GOMES, 1966). Considerou-se como semente germinada, aquela que apresentasse radícula com $5 \mathrm{~mm}$ de comprimento. As sementes foram armazenadas em saco de papel e colocadas em local arejado.

\section{RESULTADOS E DISCUSSÃO}

\section{Tempo de embebição}

Através da TABELA 1 e Figura 1, podese verificar a existência de um aumento do peso das sementes, com o decorrer do tempo de embebição; no entanto, o aumento de peso a partir das 90 horas de embebição, tornou-se muito pequeno.

Desse resultado pode-se concluir que, para uma melhor e rápida germinação das sementes de macadâmia (Macadamia integrifolia Maiden \& Betche), a embebição destas em água ou nas soluções de tratamento que se queira realizar, durante 90 horas, é suficiente.

Este resultado não concorda com os obtidos por OJIMA et a. (1976), os quais recomendam, como pré-tratamento, a embebição das sementes de macadâmia durante 48 horas. Através da Figura 1 pode-se verificar que, nesse momento, ainda é alta a absorção de água pelas sementes; talvez seja esta a razão pela qual, esses autores relataram que 0 início da germinação ocorreu somente 40 dias após a semeadura.

\section{Viabilidade das sementes}

Observando-se a TABELA 2 e a Figura 2 , pode-se verificar que houve influência do armazenamento, sobre a germinação das sementes de macadâmia. Através da Figura 2, observa-se que o mês onde ocorreu a maior porcentagem de germinação foi setembro (85\%), 4 meses após a colheita das sementes.

Após esse mês, a porcentagem de germinação sofreu queda paulatina sendo que em março (11 meses de armazenamento), se encontrava próxima a zero. 


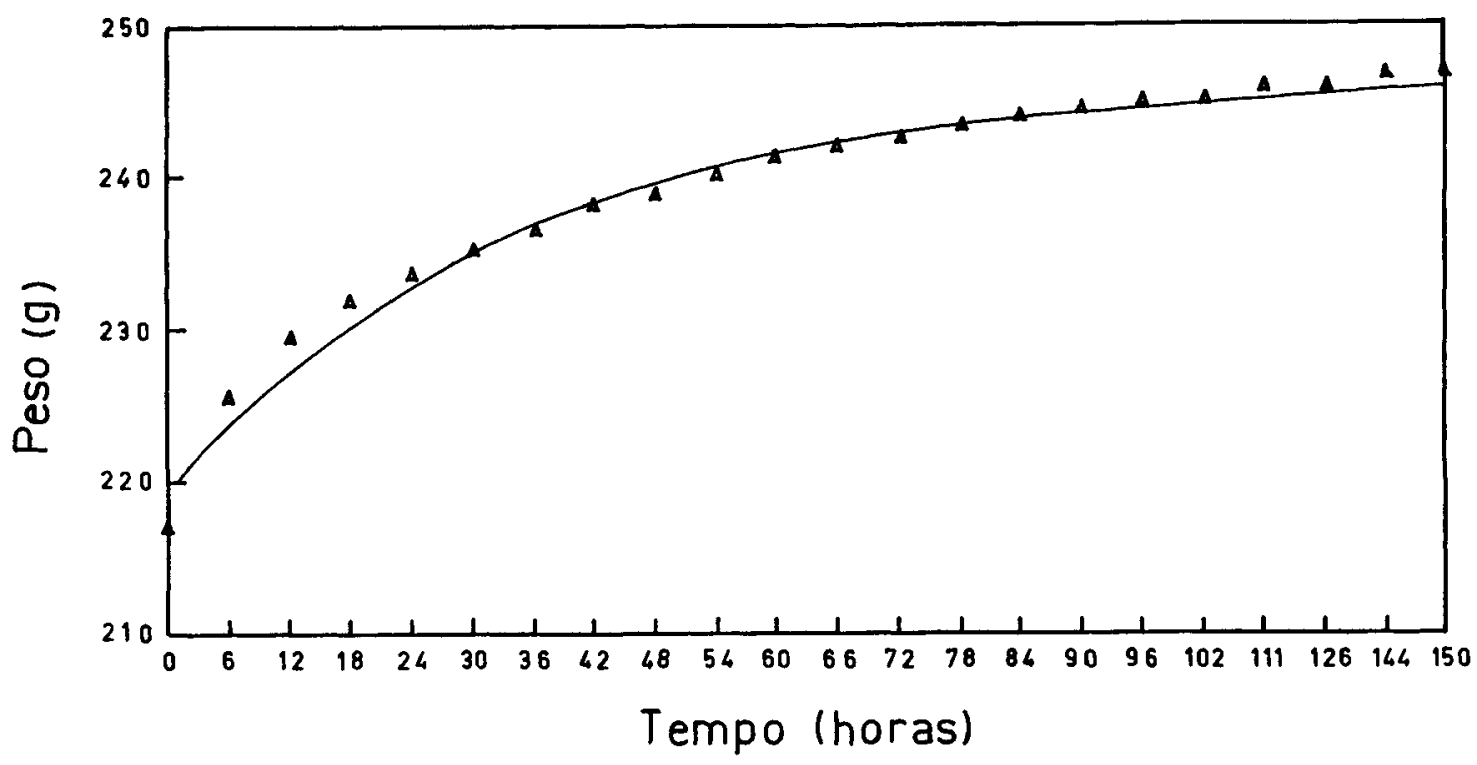

A Peso observado Peso ajustado

Figura 1 - Peso (em g), das sementes de macadâmia em embebição, até atingirem o peso constante.

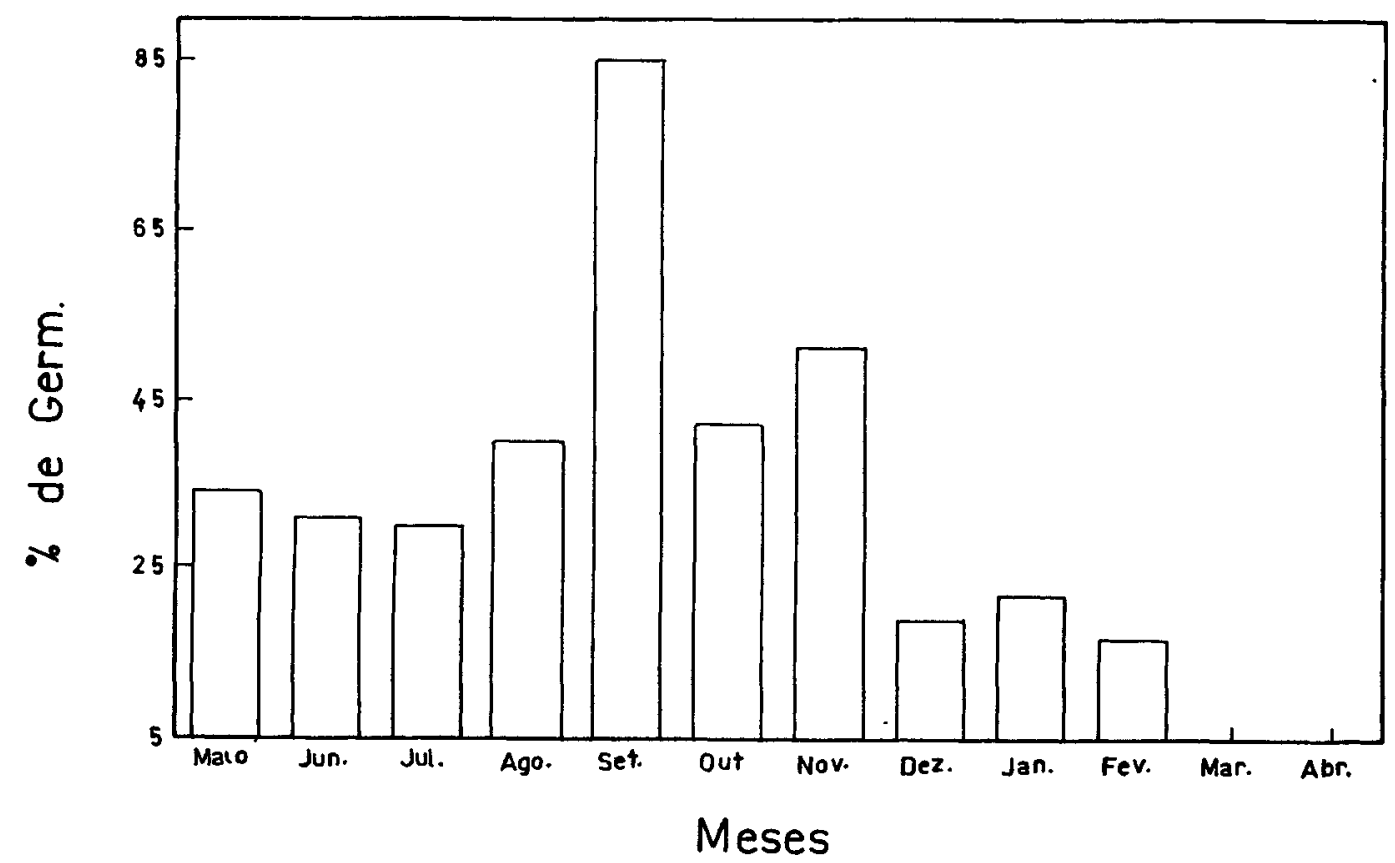
Figura 2 - Porcentagem de setnentes de macadâmia germinadas, no período de 12 meses, a partir da sua
coleta.

Sci. agric., Piracicaba, 50(1):40-44, fev./maio, 1993 
TABELA 1 - Média dos pesos das 30 sementes de macadâmia, expressos em gramas, durante a embebição, mais os pesos ajustados pela equação de Mitscherlich.

\begin{tabular}{|c|c|c|}
\hline $\begin{array}{l}\text { Tempo } \\
\text { (horas) }\end{array}$ & $\begin{array}{c}\text { Peso Observado } \\
\text { (g) }\end{array}$ & $\begin{array}{c}\text { Peso } \\
\text { Ajustado }\end{array}$ \\
\hline Peso Inicial & 216,83 & 219,57 \\
\hline 06 & 225,37 & 223,83 \\
\hline 12 & 229,35 & 227,41 \\
\hline 18 & 231,75 & 230,42 \\
\hline 24 & 233,41 & 232,94 \\
\hline 30 & 234,98 & 235,06 \\
\hline 36 & 236,36 & 236,84 \\
\hline 42 & 237,88 & 238,33 \\
\hline 48 & 238,73 & 239,59 \\
\hline 54 & 239,92 & 240,64 \\
\hline 60 & 240,93 & 241,52 \\
\hline 66 & 241,86 & 242,27 \\
\hline 72 & 242,39 & 242,89 \\
\hline 78 & 243,04 & 243,41 \\
\hline 84 & 243,74 & 243,85 \\
\hline 90 & 244,24 & 244,22 \\
\hline 96 & 244,63 & 244,53 \\
\hline 102 & 244,90 & 244,79 \\
\hline 114 & 245,68 & 245,19 \\
\hline 126 & 245,66 & 245,47 \\
\hline 144 & 246,36 & 245,75 \\
\hline 150 & 246,38 & 245,81 \\
\hline
\end{tabular}

Além disso, pode-se verificar que a partir do més de maio, ocorreu um aumento da porcentagem de germinação até um máximo em setembro. Portanto, nas condições deste experimento e para sementes de macadámia, variedade IAC-4-20, pode-se concluir que a viabilidade máxima dessas sementes é atingida 4 meses após a colheita.

Autores' como HAMILTON \& FUKUNAGA (1959) e OJIMA et al. (1976), observaram que a viabilidade máxima das sementes de macadâmia $e ́$ atingida em torno de 4 a 5 meses após o início do armazenamento, caindo bruscamente após esse período, sendo praticamente nula aos doze meses. Ainda, SIMÃo (1971) recomenda a semeadura de sementes de macadâmia, dentro de 3 a 4 meses após a colheita. Dessa forma, os dados encontrados neste trabalho corroboram os relatos dos autores citados.

TABELA 2 - Análise de variância (teste F) para os dados obtidos para porcentagem de sementes de macadâmia, germinadas no período de 12 meses, a partir da sua coleta em maio e comparação das médias pelo teste Tukey $(p<0,01)$.

\begin{tabular}{cll}
\hline \hline Causa da Variação & G.L. & F \\
\hline Meses & 11 & $22,97^{* *}$ \\
Residuo & 12 & \\
\hline Total & 23 \\
\hline Meses & Média \\
\hline Maio & $34 \mathrm{bc}$ \\
Junho & $31 \mathrm{bc}$ \\
Julho & $30 \mathrm{bc}$ \\
Agosto & $40 \mathrm{bc}$ \\
Setembro & $85 \mathrm{a}$ \\
Outubro & $42 \mathrm{bc}$ \\
Novembro & $51 \mathrm{~b}$ \\
Dezembro & $19 \mathrm{~cd}$ \\
Janeiro & $22 \mathrm{~cd}$ \\
Fevereiro & $17 \mathrm{~cd}$ \\
Março & $5 \mathrm{~d}$ \\
Abril & $5 \mathrm{~d}$ \\
\hline \hline
\end{tabular}




\section{CONCLUSÕES}

- O máximo teor de água das sementes de macadâmia, durante a fase de embebição, é atingido 90 horas após o início do processo.

- A máxima germinação das sementes de macadâmia ocorre aos 4 meses de armazenamento após a colheita.

\section{REFERENCIAS BIBLIOGRÁFICAS}

DIERBERGER, J.E.; MARINO NETTO, L.M. Noz macadâmia: uma nova opção para a fruticultura brasileira. Săo Paulo : Nobel, 1985. 120p.

GOMES, F.P. Curso de estatistica experimental. 3.ed. Piracicaba : ESALQ, 1966. 404p.
HAMILTON, R.A.; FUKUNAGA, E.T. Growing macadamia nuts in Hawaii. Hawaii Agricultural Experiment Station, Honolulu, v.121, p.1-51, 1959.

OJMA, M.; DALL ORTO, F.A.C.; RIGITANO, 0. Estudos sobre alguns aspectos da germinação das sementes da nogueira-macadâmia. In: CONGRESSO BRASILEIRO DE FRUTICULTURA, 3., 1975, Rio de Janeiro. Anais ... Campinas : SBF, 1976. v.2, p.559-566, 1976.

SIMÃo, S. Manual de Fruticultura. São Paulo ; Ceres, 1971.

Trabalho entregue para publicação $\mathrm{em} 12.06 .92$

Trabalho aprovado para publicação em 12.08 .92 